\title{
Poly Cystic Ovarian Syndrome: A Short Notes Victoria Miles*
}

Director, Baby Farm Group ${ }^{\mathrm{TM}}$ Ltd, England, UK

\section{Opinion}

Once again natural management of symptomatic and lifestyle dependant illness can be seen as a bit of an industry pioneer in terms of results. In my field of fertility related illness and disease the correctly implemented and managed system of drug free intervention has quite unnatural results.

Let's take a look specifically at PCOS an area in which i have long established and accountable, proven results.

PCOS is a condition linked to poor fertility, but it does have other implications that are likely to affect a woman on a day to day basis.

Simply put the cysts appear on the ovaries when the body has developed a difficulty in managing natural insulin levels. This is not to be confused with diabetes. Diabetes is the inability to produce and to moderate usage and production of insulin.

PCOS suffers will have higher than normal insulin levels that are associated with the production of hormones such as progesterone. High progesterone in a woman leads to many symptoms but the common ones are weight issues, facial hair, thinning scalp hair, acne and irregular periods.

In all subjects under my care the insulin increases can be attributed to high sugar intake and poor lifestyle choices.

Once ovaries are poly cystic you will always have the potential to become symptomatic.

Some of the women I have worked with are unaware if there is a family history of PCOS, some say not and others say there was a diagnosis on the maternal side of the family.

As a result of this I choose to ignore the DNA linked theory behind PCOS and work with each individual case as a separate entity.

There is one thing that will never change with PCOS with both medical and natural intervention. Unless the subject removes the poor nutrition to a high degree the symptoms will remain.

I see an improvement within the first 6 weeks with all of my PCOS clients across the board.

While medical intervention might be the obvious choice so that hormones are regulated fast and without lifestyle changes, this will not improve fertility and nor will it manage the condition on a longterm basis. With poor menstrual cycles comes irregular or completely missed ovulation. The most frequently used drug in fertility related PCOS issues is Clomid. Statistically the drug claims that $70 \%$ to $80 \%$ of patients will ovulate after taking one treatment cycle. Positive ovulation is not let's face it the same as falling pregnant. The statistics for pregnancy are more, shall we say unclear, stating that most women have a $50 \%$ chance of conceiving within the first six months of taking Clomid. What this actually means is statistically you are most likely to conceive when you are no longer taking the drug. Another common drug given to PCOS suffers is Metformin. While this is not an approved method it helps regulate the insulin levels as it is prescribed to Diabetes type 2 patients and indeed has a higher statistical change of seeing a positive pregnancy test. Let me be clear with something here though.
Many of my clients will not be maintaining anywhere near enough sexual intercourse so irrespective of medical or natural intervention this factor must be looked at very closely. A routine of sex on alternate days needs to be established to ensure they are not missing any possible ovulation occurrences.

I have and always will say weight is not my business. Nutrition and lifestyle is however what makes PCOS your life or something you learn to live with and keep under control. Without controlling the following aspects, the long-term management is particularly unlikely to be successful.

\section{Triggers for symptoms linked to PCOS are:}

Alcohol. Intake needs to be zero! Processed foods are best avoided and sugary food should be kept to a very bare minimum. Regular exercise must be maintained and particular care must be taken to drink the necessary fluids (water) on a daily basis.

All my clients that have stuck to the lifestyle changes rigidly have succeeded with achieving pregnancy.

It is very important to understand that making these changes is incredibly stressful for the majority of people and often the removal of sugar and alcohol is too much of a challenge.

One of the things $i$ contribute to the success of my clients is the regular contact and treatment using holistic therapies. The intervention increases the client's ability to stay on track and a good therapist will foresee any potential for problems and keep the client on track as best as possible. As is the case with medical intervention there will always be the potential to not find a good balance, but the wonderful difference with natural intervention is that there are an almost endless number of avenues to pursue.

*Corresponding author: Victoria Miles, Director, Baby Farm Group ${ }^{\mathrm{TM}}$ Ltd, England, UK, Tel: + 02920514044, 07973705961; E-mail: victoria@babyfarmgroup.com

Received February 24, 2017; Accepted March 18, 2017; Published March 20, 2017

Citation: Miles V (2017) Poly Cystic Ovarian Syndrome: A Short Notes. J Mol Biomark Diagn 8: 322. doi: 10.4172/2155-9929.1000322

Copyright: @ 2017 Miles V. This is an open-access article distributed under the terms of the Creative Commons Attribution License, which permits unrestricted use, distribution, and reproduction in any medium, provided the original author and source are credited. 